\title{
ASSÉDIO MORAL NO AMBIENTE DE TRABALHO
}

\author{
Amanda Vasconcelos Campos Gomes, Gabriela Aparecida Pain, Mari Angela Pelegrini \\ Universidade do Oeste Paulista - UNOESTE, curso de Direito, Presidente Prudente, SP. E-mail: \\ ammandagomes@hotmail.com
}

\section{RESUMO}

O objetivo desse estudo é analisar o denominado assédio moral presente no ambiente de trabalho empresarial, envolvendo a relação de emprego, tanto entre o trabalhador e seu superior hierárquico, bem como entre os colegas de trabalho, ou entre eles e seus superiores hierárquicos, e suas consequências, apresentando discussão conceitual, verificando e refletindo sobre as formas de apresentação do assédio moral no ambiente de trabalho, bem como sobre os seus efeitos e consequências no âmbito jurídico, em face da Constituição Federal e seus princípios. A conclusão constatou que, não obstante ainda persista a incidência de casos, ela diminuiu nos últimos anos em razão da conscientização dos trabalhadores.

Palavras-chave: Assédio. Moral. Trabalho. Dignidade. Ambiente

\section{BULLYING IN THE WORKPLACE}

\section{ABSTRACT}

The objective of this study is to analyze the so-called moral harassment in the workplace, involving the employment relationship between the worker and his / her superior, as well as between coworkers or between them and their hierarchical superiors, and their Consequences, presenting a conceptual discussion, verifying and reflecting on the forms of presentation of moral harassment in the work environment, as well as on its effects and consequences in the legal scope, in the face of the Federal Constitution and its principles. The conclusion was that, despite the persistence of cases, it has declined in recent years because of the workers' awareness.

Keywords: Harassment. Moral. Work. Dignity. Environment

\section{INTRODUÇÃO}

No âmbito da moderna relação de emprego a prática do assédio moral foi objeto de estudos significativos nos últimos anos, mas ainda se encontra uma boa parcela de trabalhadores em ambientes de trabalho enfermos e degenerados, o que, consequentemente, ainda leva a necessidade de reflexão diante da sociedade, para que a população, inclusive a classe de empregadores, tome ciência da sua ilegalidade e quais as consequências na esfera jurídica, visando com isso a melhoria da saúde física e mental dos trabalhadores e, por tabela, do próprio empreendimento econômico.

Diante da problemática apresentada, verifica-se e objetiva-se dar grande importância na exposição do tema, posto que é de extrema relevância para a comunidade científica, jurídica e acadêmica, além da sociedade em geral.

\section{METODOLOGIA}

O estudo foi desenvolvido pela utilização de bibliografia jurídica, incluindo revistas, doutrinas e artigos eletrônicos, além de legislação nacional vigente, através de leitura exploratória. A discussão foi formulada a partir do raciocínio dedutivo, partindo da argumentação 
geral (como se desenvolve o assédio moral e suas consequência genéricas) para argumentos particulares (sua ocorrência no âmbito empresarial e quais são as penalidades aplicáveis atualmente), além de expor o objeto tratado valendo-se do método dialético, demonstrando, ainda, dados qualitativos, para melhor compreensão do tema.

\section{RESULTADOS}

O presente estudo visa a análise do assédio moral presente no ambiente de trabalho empresarial, pela situação em que se encontra os empregados na relação de trabalho moderno.

Busca-se informar e cientificar a comunidade jurídica (discente e profissional) sobre a presença e consequências do assédio moral nas relações de emprego, estimulando debates e palestras, e ainda, quanto a sua importância e contribuição social, vê-se que se trata da realidade vivenciada por muitos empregados pressionada e lesada por esse tratamento degradante, o que consequentemente, acaba por ser necessário a sua reflexão, visando alertar e conscientizar a população sobre seus efeitos através do levantamento da questão à sociedade.

\section{DISCUSSÃO}

O ambiente de trabalho moderno tem sido alvo de grandes mudanças desde que a globalização passou a agir e produzir efeitos, e uma dessas mudanças é a presença do assédio moral. (NETO; CAVALCANTE, 2016), cuja conceituação vale a pena destacar.

Assédio moral, de acordo com Martins (2012), consiste na ação ou omissão de natureza psicológica e repetitiva cometida pelo empregador ou seus prepostos, seja dolosa ou culposamente, ofendendo com isso a dignidade, personalidade e integridade do trabalhador, que, com essa prática, é humilhado e constrangido durante a jornada de trabalho e no exercício de suas funções.

É de se observar que, a despeito dos denominados poderes do empregador (direção, gerência, fiscalização e organização, entre outros) o ato abusivo, ao reiteradamente exigir produtividade de forma exacerbada e além das forças, utilizando métodos vexatórios, por exemplo, não constitui um dos poderes do empregador e sim a extrapolação de limites que são objeto de investigação na ciência do direito que prevê punições aos infratores.

Referida conduta demonstra um desacerto e não age o empregador, ou seus prepostos, nos limites de sua autoridade. Age com abusividade e como ensinam os doutrinadores: "Por abusividade de conduta intencional, entende-se como sendo aquela que extrapola os poderes da chefia, visando, exclusivamente, denegrir o trabalhador na sua esfera pessoal". (PANPLONA FILHO; BARROS, 2013, p. 585).

Desta forma, quando alguns empregadores, pois de fato não são todos, agem em desacordo com o limite do poder de direção e comando entendendo, equivocadamente, terem o poder de submeter o seu subordinado a algum tipo de tratamento humilhante, gera consequências nefastas, tanto no âmbito interno em face do empregado (atua de forma inconsequente trazendo ingerência no campo psíquico ou mental), quanto externo, pois denigre o ambiente de trabalho com consequências materiais prejudiciais ao empregador, pois no âmbito jurídico, aquele que se sentir lesado pode questionar o ato na Justiça do Trabalho e sendo vitorioso em ações trabalhistas, gerará custos, algumas vezes vultuosos a título de indenizações, para o empregador,.

Nesta linha de raciocínio, leciona Guedes (2003) ao evidenciar que, "o assédio moral, na verdade, decorre de atitude deliberada de um perverso cujo objetivo é destruir a vítima e afastá-la do mundo do trabalho", nem sempre o empregador tem a exata noção de que um de seus prepostos pode estar cometendo algum tipo de assédio e sofrerá a consequência apenas quando acionado na justiça. 
Por outro lado, quanto à pessoa do empregado, maior vítima de assédio, tem sido frequente a tentativa de transferir a ele a culpa e é interessante a incidência de vítimas dentro de uma repetição de ocorrências, com várias características em comum. Neste sentido afirma Hirigoyen:

[...] É caracterizado como uma pessoa fraca, com pouca confiança em si mesma e que desempenha suas funções de modo incorreto; tais deficiências podem torna-lo um alvo fácil ao assédio moral. Já os com inúmeras qualidades profissionais e pessoais, geram sentimento de ciúme e inveja, tornando-se também alvo. Outra característica seria a faixa etária: a mais atingida situa-se entre 40 e 55 anos, pois são considerados como detentores de desempenho inferiores em relação aos mais jovens. (apud SOSSELA; NEVES, 2013, p. 24).

Tal prática extrema leva à degradação do empregado enquanto ser humano, e conforme a Organização Internacional do Trabalho (2003), traz consequências ruins aos empresários:

\{...] a ocorrência do Assédio Moral no Trabalho poderá causar baixa produtividade, diminuição de benefícios, maiores custos de seleção e formação de pessoal substituto; para o Governo, acarreta gastos com a saúde do trabalhador. $\mathrm{O}$ assédio moral pode ser ligado e encontrado no ambiente em que o trabalho é exercido (pois é nele praticado), dessa forma, faz-se necessário iniciar com a evolução da própria relação de trabalho, entre empregador e empregado.

Nas palavras de outros estudiosos do assunto, por exemplo Garcia (2016), destaca que a prática de humilhação e assédio moral relacionado ao trabalho não é fato novo. É sabido que na sociedade pré-industrial, fato público e notório, existiu a escravidão. O trabalhador era considerado como coisa, e não sujeito de direito, como se verifica nas civilizações antigas da Grécia, Roma, e Egito.

Assim, desde os seus primórdios o trabalho vem sendo exercido de certo modo e sob num ritmo acelerado visando a produção acima de tudo e a qualquer preço, onde, num primeiro momento, reinou a escravidão e servidão. O homem era visto, enfim, como um mero objeto e o que importava era sua força de trabalho.

Tal sistema perdurou até o surgimento das chamadas corporações de ofício, onde se tinha as figuras dos mestres, companheiros e aprendizes. "Havia nessa fase da história um pouco mais de liberdade ao trabalhador; os objetivos, porém, eram os interesses das corporações mais do que conferir qualquer proteção aos trabalhadores". (MARTINS, 2015, p. 4).

O século XVIII, por sua vez, foi marcado por um grande acontecimento, como menciona Gustavo Filipe Barbosa Garcia (2016, p.29), "Com a Revolução Francesa foram suprimidas as corporações de ofício, tidas como incompatíveis com o ideal de liberdade individual da pessoa".

Os ideais de Liberdade, Igualdade e Fraternidade, fez surgir uma nova visão no que diz respeito à dignidade com a Declaração Universal dos Direitos do Homem e do Cidadão.

Uma extraordinária mudança surgiu, pois, com a Revolução Industrial que nas palavras dos doutrinadores inicia uma nova fase capitalista onde floresceram os exageros e o próprio assédio moral: "Com a criação de novas técnicas de produção, com a criação de máquinas, a humanidade inicia uma nova ordem natural dos acontecimentos econômicos a qual leva a uma única direção: a produção em massa e o acúmulo de capitais". (NETO; CAVALCANTE, 2015, p. 3).

O modo de produção atingiu proporções nunca vistas antes, porém o ser humano foi submetido a jornadas de trabalho completamente desgastantes, e condições de trabalho 
desumanas, tudo em nome do radiante desenvolvimento. Não existiam direitos trabalhistas naquela época, o que importava era produzir.

Mais tarde, porém, surge a Declaração Universal dos Direitos Humanos onde em seu Art. $1^{\circ}$ estabelece: "Todos os seres humanos nascem livres e iguais em dignidade e em direitos. Dotados de razão e de consciência, devem agir, uns para com os outros em espírito de fraternidade". (DECLARAÇÃO UNIVERSAL DOS DIREITOS HUMANOS, 1948).

Tal ideal foi integrado na Constituição Federal de 1988 em seu art. $1^{\circ} \mathrm{III}$ e IV, ao mencionar que a República Federativa do Brasil tem como Fundamentos a dignidade da pessoa humana e os valores sociais do trabalho e da livre iniciativa da mesma forma encontrados nos arts. $3^{\circ}$, I e IV e $4^{\circ}$, II. (BRASIL, 1988).

Pois bem, uma vez que tal princípio, dignidade humana, encontra-se consagrado na Magna Carta, tem-se que ele deve ser ele refletido na sociedade, inclusive no que diz respeito ao ambiente de trabalho, e quanto a isto, como bem registra a doutrina "Pode-se dizer, sinteticamente, que a dignidade do trabalhador decorre do princípio constitucional que tutela os valores pessoais dos trabalhadores, sejam eles religiosos, morais, dentre outros". (PANPLONA FILHO; BARROS, 2013, p. 590). Pois no que antes se tinha a relação de escravo e senhor, hoje se tem uma relação de emprego, protegida pelo Estado e pelos direitos trabalhistas.

Por outro lado, referindo-se ao próprio ambiente de trabalho em condições melhores que permitam o exercício desta dignidade, ensina Garcia:

[...] Cabe frisar que, obviamente, a situação ideal - a qual deve ser sempre buscada - é aquela em que as condições de trabalho, quanto ao ambiente em que as atividades são desempenhadas, não sejam penosas, nem apresentem qualquer fator de periculosidade e insalubridade. (2016, p. 49).

Sendo, portanto, um local frequentado diariamente, nada há de mais degradante do que realizar uma atividade laborativa em um ambiente em que, constantemente, está presente um comportamento lesivo.

No "comportamento degradante" insere-se o próprio assédio moral, definido por MarieFrance Hirigoyen (apud PANPLONA FILHO; BARROS, 2013, p. 584) como:

Palavras, gestos, escritos que possam trazer dano à personalidade, à dignidade, ou à integridade. Toda e qualquer conduta abusiva manifestando-se sobretudo por comportamentos que fira a integridade física ou psíquica de uma pessoa, por em perigo seu emprego ou degradar seu ambiente de trabalho.

Assim, tem-se como sendo condutas eivadas de certa perversidade que visam a lesão, seja física ou moral da pessoa a ser atingida, alvo do assédio.

Conclui-se, portanto, que três são os principais elementos caracterizadores do assédio moral, segundo Rodolfo Mário Veiga Pamplona Filho e Renato da Costa Lino de Goes Barros, "(a) abusividade da conduta intencional; (b) repetição e prolongamento; e (c) ataque a dignidade do trabalhador". (2013, p. 584).

Com relação ainda assédio moral, é interessante as variações de conceitos quanto a forma em que tais comportamentos podem se manifestar dentro do ambiente de trabalho:

O assédio moral pode ser: (a) vertical - pressupõe uma relação de autoridade, com o predomínio do desmando, da competitividade e da instauração do medo pelo superior em relação ao subordinado; (b) horizontal - é o que se instaura em pessoas de mesma hierarquia, tendo 
como característica básica a pressão para produzir com qualidade e baixo custo. É a humilhação presente nas relações cotidianas entre os mais produtivos e os menos produtivos; (c) combinado - é o que se dá quando o chefe e os outros empregados estabelecem uma união com o propósito de humilhar uma pessoa, visando a sua exclusão da empresa; (d) ascendente um subordinado ou um grupo de empregados que desejam a saída do superior (chefe) da empresa. (NETO; CAVALCANTE, 2016, p. 370).

Visto o conceito do instituto, bem como as variadas situações em que ele pode ocorrer, importante saber, agora, quem pode ser sujeito ativo e passivo deste fenômeno. Para isso importa destacar os conceitos de quem são os sujeitos da própria relação de emprego, para melhor compreender os mesmos sujeitos do assédio, que a rigor, confundem-se.

Ensina 0 art. $3^{\circ}$ da CLT, as características do empregado: "Considera-se empregado toda pessoa física que prestar serviços de natureza não eventual a empregador, sob a dependência deste e mediante salário".

E ainda, em seu art. $2^{\circ}$ do mesmo diploma consolidado, define a figura do empregador: "A empresa, individual ou coletiva, que assumindo os riscos da atividade econômica, admite, assalaria e dirige a prestação pessoal de serviços". Há polêmica em relação a pessoa jurídica, supostamente impossível de ser objeto de assédio moral, pelo menos em tese. A corrente dominante entende que ela não esta sujeita a prática de atos da natureza em que se apresenta no assédio moral, eles se exteriorizam pela pessoa do empresário (pessoa física). (CONSOLIDAÇÃO DAS LEIS TRABALHISTAS, 1943).

Estudiosos revelam que o assédio moral foi acentuado pela era globalizada. De acordo com essa corrente de pensamento, tal comportamento reprovável, impregnado em grande parte das relações de trabalho, foi desencadeado pela chamada globalização, evento transformador das atividades econômicas e responsável pelo modo de produção atual. Neste sentido, menciona Neto e Cavalcante (2016, p.369):

A globalização, com base em novas técnicas de seleção, inserção e avaliação do indivíduo no trabalho, fez uma reestruturação nas relações de trabalho. O novo paradigma é o 'sujeito produtivo', ou seja, o trabalhador que ultrapassa metas, deixando de lado sua dor ou a de terceiros. É a valorização do individualismo em detrimento do grupo de trabalho. $\mathrm{O}$ individualismo exacerbado reduz as relações afetivas e sociais no local de trabalho, gerando uma série de atritos, não só entre as chefias e os subordinados, como também entre os próprios subordinados.

Quanto a esta mudança e influência da globalização, ainda mencionam Sossela e Neves:

O neoliberalismo estabelece condições econômicas que podem ser caracterizadas por: precariedade de emprego, flexibilidade das relações de trabalho, ritmo acelerado da economia, interesse por reduzir custos de trabalho, existência de desemprego, manifestação da terceirização, crescimento do setor informal, entre outros fatores. (2013, p.25)

Este cenário demonstra a infeliz realidade em que se encontram os membros que compõem o ambiente de trabalho hodiernamente, uma luta desenfreada pela aceleração e exploração da mão de obra, principalmente no que diz respeito ao empregado, pois a este, impera a submissão, como destaca outro renomado jurista. De acordo com Martins (2016, p. 149): 
Subordinação é a obrigação que o empregado tem de cumprir as ordens determinadas pelo empregador em decorrência do contrato de trabalho. É o estado jurídico em que se encontra o empregado em relação ao empregador. É o objeto do contrato de trabalho. Subordinação é submissão do empregado ao poder de direção do empregador.

Trata-se de elemento comum e caracterizador da relação de emprego, e é, portanto, a relação de sujeição, a que Martins também chama de poder de controle. Eis a submissão.

Constatado o ambiente hostil, subordinado, o assédio, por se tratar de atos naturalmente degradantes tanto fisicamente, mas principalmente, psicologicamente, é certo que as suas lesões seriam tão maléficas e resultantes em tantos danos quantos foram os atos. Sobre essas consequências decorrentes, assim se manifestou importante doutrinadores já citados:

As consequências dessas tensões (=pressões) repercutem na vida cotidiana do trabalhador, com sérias interferências na sua qualidade de vida, gerando desajustes sociais e transtornos psicológicos. Há relatos de depressão, ansiedade, e outras formas de manifestação (ou agravamento) de doenças psíquicas ou orgânicas. Casos de suicídio têm sido relatados, como decorrência dessas situações. (NETO; CAVALCANTE, 2016, p. 370).

No que diz respeito ao âmbito de alcance das consequências de atos de assédio moral, pode-se verificar que elas não se restringem ao ambiente de convivência do lesado, muito menos ao local de trabalho, porém ela reflete na própria economia, não apenas no que tange a empresa, mas também, segundo afirma Guedes (apud SOSSELA; NEVES, 2013, p. 24):

Algumas Empresas utilizam-se do Assédio Moral sendo que tal ação prejudica o seu próprio funcionamento e cita que um trabalhador submetido à violência psicológica tem rendimento inferior a $60 \% \mathrm{em}$ termos de produtividade e eficiência em relação a outros trabalhadores e seu custo para o empregador é de $180 \%$ a mais.

Destarte, visto que tais atos são geradores de tão grandes males, é certo que não hão de ficar impunes, pelo contrário, farão jus à indenização devida, sem prejuízo de demais valores a serem ressarcidos. Neste sentido pontua Neto e Cavalcante:

O assédio enquadra-se nas hipóteses do art. 483, a e b, da CLT, ou seja, quando o empregador, direto ou indiretamente, exigir do empregado serviços superiores às suas forças ou alheios ao contrato ou for tratado com rigor excessivo. O empregado, vítima de assédio moral, deve procurar a Justiça do Trabalho, pleiteando a indenização relativa ao dano moral. É inegável que o assédio moral ocasiona danos à imagem, à honra, à liberdade do trabalhador ( $\operatorname{art} .5^{\circ}, \mathrm{V}$ e X, CF), logo a sua reparação é questão de justiça (art.186, CC). O empregado cumulará os pedidos de rescisão indireta do contrato de trabalho e do dano moral. (2016, p. 371).

Por fim, vê-se, portanto, a necessidade de reparação do dano causado ao empregado (ou em raras vezes, ao empregador), cujo amparo legal tem sido objeto de constantes condenações no âmbito do judiciário, tanto na esfera trabalhista como na esfera cível, como revela esta ementa de decisão do conhecido doutrinar (atualmente ministro do STF), Alexandre de Moraes: "Como decidiu o Superior Tribunal de Justiça, sobrevindo em razão de ato ilícito, perturbações nas relações psíquicas, na tranquilidade, nos sentimentos e nos afetos de uma pessoa, configura-se o dano moral, passível de indenização". (apud PAMPLONA FILHO; BARROS, 2013, p. 591). 
Lesiona-se a esfera íntima do trabalhador, normalmente o assediado, na maioria dos casos que batem às portas do judiciário trabalhista violando, por via oblíqua, o direito, constitucionalmente consagrado, ou seja, o princípio da Dignidade da Pessoa Humana, e isto, em um Estado Democrático de Direito, é inadmissível.

\section{CONCLUSÃO}

Diante do exposto, verifica-se que o assédio moral se encontra no ambiente de trabalho sempre que presente um comportamento degradante, praticado reiteradas vezes e cujo objetivo é a humilhação e degradação constante da vítima assediada, parta ele do empregador, ou do próprio empregado, tanto nas formas horizontais ou verticais, ascendente ou descendente, conforme a posição da vítima assediada e o assediador. Trata-se, portanto, de uma necessidade premente no seio empresarial de investir na prevenção desta conduta, pois é umas das principais causas de adoecimento envolvendo os atores sociais das relações de trabalho e, por via de consequência, trazendo prejuízos aos trabalhadores e também aos empresários, que, via de regra, são condenados na Justiça do Trabalho ao pagamento de vultosas quantias indenizatórias pelo comportamento irregular de seus sócios ou prepostos, quando não o próprio empregador pessoa física, podendo inviabilizar, inclusive a continuidade de seus negócios.

\section{REFERÊNCIAS}

BRASIL. Consolidação das leis do trabalho. Decreto-Lei no 5.452, de 1 de mai. de 1943. Das Normas Gerais de Tutela do Trabalho. Disponível em: http://www.planalto.gov.br/ccivil_03/decreto-lei/Del5452.htm. Acesso em 5 de mar. de 2017.

BRASIL. Constituição (1998). Constituição da República Federativa do Brasil. Brasília: Senado Federal, 1988.

CAVALCANTE, Jouberto de Pessoa; JORGE NETO, Francisco Ferreira. Curso de direito do trabalho. 3. ed. São Paulo: Atlas, 2015.

GARCIA, Gustavo Barbosa. Curso de direito do trabalho, 10a ed. Rio de Janeiro: Forense, 2016.

MARTINS, Sergio Pinto. Direito do trabalho, 31 ed. São Paulo: Atlas, 2015.

ONU. Declaração Universal dos Direitos Humanos. Disponível em: http://unesdoc.unesco.org/images/0013/001394/139423por.pdf. Acesso em 12 de mar. de 2017.

PAMPLONA FILHO, Rodolfo Mário Veiga; BARROS, Renato da Costa Lino de Goes. A distinção do assédio moral de figuras afins. Brasília, v. 14 n. 104. Out. 2012/Jan. 2013.

SOSSELA, Michelle Leitão; NEVES, Eduardo Borba. As consequências do assédio moral para trabalhadores, organização e governo. Revista UNIANDRADE V.12, n.1, p.18-31. 2011. 